\section{Dementia caregiver burden: reliability of the Brazilian version of the Zarit caregiver burden interview}

\author{
Sobrecarga do cuidador de pacientes com \\ demência: confiabilidade da versão brasileira \\ do inventário de sobrecarga de Zarit
}

Anita Taub 1,2

Sergio B. Andreoli 3

Paulo H. Bertolucci 4

\footnotetext{
1 Hospital Israelita Albert Einstein, São Paulo, Brazil.

2 Universidade Federal de São Paulo, São Paulo, Brazil.

3 Núcleo de Estatística e Metodologia Aplicada Departamento de Psiquiatria, Universidade Federal de São Paulo, São Paulo, Brazil.

4 Departamento de Neurologia e Neurocirurgia Universidade Federal de São Paulo, São Paulo, Brazil.

Correspondence Anita Taub

Rua Capitão Antônio Rosa 151/21, São Paulo, SP 01443-010, Brasil. anitaub@einstein.br
}

\begin{abstract}
The object of this article is to examine the reliability of the Brazilian version of the Zarit Caregiver Burden Interview (ZBI). The instrument is a 22-item scale assessing the extent to which caregivers view their responsibilities as having an adverse impact on their social life, health, emotional well-being, and finances. We assessed 50 primary informal caregivers of demented patients coming from 3 different health care centers, using the test-retest method. Analysis of the results showed an intraclass reliability coefficient of 0.88, while Cronbach's coefficient alpha was 0.77 for the test and 0.80 for the retest items. The Brazilian version of ZBI shows sufficient reliability, comparable to the original version.
\end{abstract}

Dementia; Caregiver; Home Nursing

\section{Introduction}

Patients with dementia demand a great deal of care; depending on the severity of the disorder, significant changes in the family structure may be required. Very often the family is forced to reexamine the allotment of roles and obligations in daily tasks. The patient now has requirements that may range from just a little help to complete assistance to perform routine tasks such as dressing, feeding, moving, etc. A frequent occurrence during this moment of crisis is that a caregiver is chosen within the family circle. However, this new role is often taken on quite suddenly by the caregiver, who may be unprepared or inexperienced, leading to an emotional burden $1,2,3$.

The caregiver burden should thus be considered an important dimension of Alzheimer's disease, and as such calls for in-depth investigation. It is therefore essential to use objective scales to measure the caregiver burden and to design and evaluate therapeutic interventions. The object of the present study is to verify the reliability of the Brazilian version of the Zarit Caregiver Burden Interview.

\section{Instruments}

The Zarit Caregiver Burden Interview (ZBI) was developed by Zarit and coworkers in $1985^{4}$ and 
comprises 22 questions graded on a scale from 0 to 4 , according to the presence or intensity of an affirmative response. The questions refer to the caregiver/patient relationship and evaluate the caregiver's health condition, psychological well-being, finances, and social life. The caregiver burden is evaluated by means of the total score obtained from the sum total of questions. The reliability of the original version was excellent ICC (intraclass correlation coefficient = 0.71 ; alpha $=0.91$ ).

The ZBI was adapted to several languages, showing a performance similar to the original version. The reliability indicators measured by the ICC were in the 0.71 to 0.89 range, whereas internal consistency ranged from 0.85 to 0.9393 $5,6,7$. In the validation studies, the correlation was $r=0.41$ with the Brief Symptoms Inventory and $r=0.71$ with the Global Burden Index 8 .

\section{Procedures}

Caregivers were identified in three of the following health care centers: (a) the Outpatient Neuropsychology Clinic of the Mental Health Unit at Hospital Israelita Albert Einstein, São Paulo, Brazil; (b) the Informal Support Group for Dementia Patients of the Brazilian Association of Alzheimer's Disease (ABRAZ); and (c) the Outpatient Clinic on Behavioral Neurology of the Federal University in São Paulo (UNIFESP), São Paulo, Brazil. Those who were willing to participate signed a term of informed consent and were submitted to another interview within 3 to 6 days.

\section{Statistical analysis}

The analysis is divided into two parts: the descriptive study (the caregivers' sample demographic history and the patients' functional and clinical history) and reliability study. Three analytical procedures were used to calculate the reliability indicators: (1) an estimate of the intraclass correlation coefficients of the instrument's total score 9; (2) the internal consistency measured by Cronbach's coefficient alpha 10; (3) an estimate of the Kappa values for each of the items in the instrument, measured by the five levels (polychotomous) and dichotomized into "present" and "absent". In order to interpret the Kappa values in the present study, they were characterized according to the levels measured by the degree of concordance coefficients proposed by Landis \& Koch 11, who suggested that values over 0.75 should be classified as "excellent" concordance, whereas values below 0.40 would be considered "poor" and those in the 0.40 to 0.75 range as "satisfactory" to "good".

\section{Results}

The ZBI was administered to a total of 50 caregivers, of whom $82 \%$ were women, ranging from 23 to 81 years of age (average age $=56$ years), with 3 to 19 years of schooling (average $=11$ years; $\mathrm{SD}=0.62$ ). Some $78 \%$ were married, $70 \%$ were housewives, and $56 \%$ were the patients' daughters. A weekly average of 111 hours was dedicated to caring for the patient; the minimum caregiving time was 1 hour and the maximum 168 hours. Sixty-four percent of caregivers received help from other family members, whereas $78 \%$ had the assistance of a hired professional.

The most prevalent disorder was Alzheimer's disease $(42 \%)$, followed by vascular dementia (8\%). Caregivers reported that $98 \%$ of these patients had deficits in orientation, whereas $100 \%$ had memory deficits, and progressive aggravation of symptoms was reported in 96\%. Language disorders were identified in $64 \%$ of the patients and $86 \%$ got lost in familiar places. As for functional characteristics, $56 \%$ required help taking a bath, $64 \%$ in getting dressed, $50 \%$ in going to the bathroom, $42 \%$ needed some kind of assistance in getting out of bed, $56 \%$ had some degree of incontinence (fecal or urinary) or occasional "accidents”, and $48 \%$ needed help feeding themselves.

The ZBI showed an ICC of 0.88 , while Cronbach's coefficient alpha was 0.77 for the test and 0.80 for the retest items. Table 1 shows the results of the reliability analysis for each of the questionnaire's items. Kappa values for most of the questions with polychotomous measurements were satisfactory. The only exceptions were questions $11(\mathrm{k}=0.54), 15(\mathrm{k}=0.59)$, and $22(\mathrm{k}=0.57)$ with good indicators and questions $3(\mathrm{k}=0.27), 7(\mathrm{k}=$ $0.39), 14(\mathrm{k}=0.29)$, and $21(\mathrm{k}=0.37)$ with poor indicators. The coefficients of questions $4,5,6,13$, and 18 could not be calculated due to the lack of variability in the answers. The kappa values for most of the dichotomized questions were "good" and "excellent" in question $22(\mathrm{k}=0.78)$. The questions that could not be evaluated on a polychotomous measurement level had coefficients ranging from "satisfactory" to "good".

Upon examining the distribution of the lowreliability answers, in question 3, "Do you feel 
Concordance/divergence distribution and the kappa reliability coefficient for each of the questions

of the caregiver burden instrument as measured in a test-retest study with 50 patients.

\begin{tabular}{|c|c|c|c|c|c|c|c|c|}
\hline & $\begin{array}{l}\text { CO } \\
\text { (poly) }\end{array}$ & $\begin{array}{c}\text { DI } \\
\text { (poly) }\end{array}$ & $\begin{array}{l}\text { Kappa } \\
\text { (poly) }\end{array}$ & $\begin{array}{c}\text { SD } \\
\text { (poly) }\end{array}$ & $\begin{array}{l}\mathrm{CO}+ \\
\text { (dic) }\end{array}$ & $\begin{array}{l}\text { CO- } \\
\text { (dic) }\end{array}$ & $\begin{array}{l}\text { kappa } \\
\text { (dic) }\end{array}$ & $\begin{array}{l}\text { SD } \\
\text { (dic) }\end{array}$ \\
\hline 1. Do you feel that your relative asks for more help than he/she needs? & 0.64 & 0.36 & 0.49 & 0.09 & 0.46 & 0.38 & 0.68 & 0.10 \\
\hline $\begin{array}{l}\text { 2. Do you feel that because of the time you spend with your relative } \\
\text { you don't have enough time for yourself? }\end{array}$ & 0.62 & 0.38 & 0.49 & 0.09 & 0.70 & 0.20 & 0.74 & 0.11 \\
\hline $\begin{array}{l}\text { 3. Do you feel stressed between caring for your relative and trying } \\
\text { to meet other responsibilities to your family or work? }\end{array}$ & 0.46 & 0.54 & 0.27 & 0.09 & 0.72 & 0.10 & 0.43 & 0.16 \\
\hline 4. Do you feel embarrassed over your relative's behavior? & 0.72 & 0.28 & - & - & 0.24 & 0.60 & 0.63 & 0.12 \\
\hline 5. Do you feel angry when you are around your relative? & 0.65 & 0.35 & - & - & 0.47 & 0.28 & 0.49 & 0.13 \\
\hline $\begin{array}{l}\text { 6. Do you feel that your relative currently affects your relationship } \\
\text { with other family members or friends in a negative way? }\end{array}$ & 0.58 & 0.42 & - & - & 0.34 & 0.40 & 0.48 & 0.12 \\
\hline 7. Are you afraid of what the future holds for your relative? & 0.56 & 0.44 & 0.39 & 0.10 & 0.86 & 0.08 & 0.69 & 0.17 \\
\hline 8. Do you feel that your relative is dependent on you? & 0.74 & 0.26 & - & - & 0.96 & 0.02 & 0.66 & 0.32 \\
\hline 9. Do you feel strained when you are around your relative? & 0.64 & 0.36 & 0.47 & 0.10 & 0.42 & 0.34 & 0.52 & 0.12 \\
\hline $\begin{array}{l}\text { 10. Do you feel your health has suffered because of your involvement } \\
\text { with your relative? }\end{array}$ & 0.64 & 0.36 & 0.40 & 0.10 & 0.30 & 0.46 & 0.51 & 0.12 \\
\hline $\begin{array}{l}\text { 11. Do you feel that you don't have as much privacy as you would like, } \\
\text { because of your relative? }\end{array}$ & 0.66 & 0.34 & 0.54 & 0.09 & 0.58 & 0.29 & 0.60 & 0.12 \\
\hline $\begin{array}{l}\text { 12. Do you feel that your social life has suffered because you are } \\
\text { caring for your relative? }\end{array}$ & 0.54 & 0.46 & 0.40 & 0.09 & 0.58 & 0.22 & 0.54 & 0.13 \\
\hline $\begin{array}{l}\text { 13. Do you feel uncomfortable about having friends over because } \\
\text { of your relative? }\end{array}$ & 0.74 & 0.26 & - & - & 0.16 & 0.64 & 0.48 & 0.14 \\
\hline $\begin{array}{l}\text { 14. Do you feel that your relative seems to expect you to care } \\
\text { for him/her as if you were the only one he/she could depend on? }\end{array}$ & 0.46 & 0.54 & 0.29 & 0.09 & 0.74 & 0.12 & 0.55 & 0.15 \\
\hline
\end{tabular}

$\mathrm{CO}=$ concordance $; \mathrm{CO}+=$ positive concordance $; \mathrm{CO}-=$ negative concordance; $\mathrm{SD}=$ standard deviation .

stressed between caring for your relative and trying to meet other responsibilities for your family or work?" the authors noted that the caregivers' feelings changed from greater stress in the first interview to less stress in the second one ( $\mathrm{n}=20$ to $\mathrm{n}=7$, ranging from "very frequently" to "always"). This alteration was mainly due to a greater number of answers expressing feelings of occasional stress ("sometimes": $n=18$ to $n=27$ ), followed by "never" ( $n=7$ to $n=12$ ). Two of the family caregivers showed quite significant changes that varied from feeling stressed "very frequently" and "almost always" to "never". This variation in the answers seems to indicate a tendency towards a decrease in the perception of stress, from the first to the second interviews.

In question 7, "Are you afraid what the future holds for your relative?" during the first interview, the caregivers were inclined to keep their answers directed towards "very frequently" or "nearly always" afraid ( $=32$ ). On the other hand, in the second interview, the answers were often altered to "sometimes" $(n=7)$, or they would change from "very frequently" to "always" afraid and vice-versa $(n=7)$. Only 3 subjects came up with a contrary alteration, from "sometimes" to "always". Only one of the family caregivers showed a significant change, from "nearly always" to "rarely". The variation in the answers to this question seems to indicate that from the first to the second interview there is a tendency towards becoming less afraid about what could happen to their relative in the future.

In question 10, "Do you feel your health has suffered because of your involvement with your relative?", in the first interview the caregivers were inclined to concentrate their answers on "never" having felt that caregiving had affected their health $(n=31)$. However, in the second interview alterations in the answers tended to show that this feeling had at the most, increased to "sometimes". However, there were no significant changes in the answers. Here, it may be noted that the family caregivers did tend to feel that their health had been affected more.

In question 12, "Do you feel that your social life has suffered because you are caring for your relative?", in the first interview the answers were distributed between "never" and "sometimes" feeling that social activities had been affected $(n=35)$. Only a few changes were 
observed in the second interview, with answers tending to concentrate more on "never" ( $\mathrm{n}=41$ "sometimes", "rarely", and "never"). There were two significant divergences. In one, the caregiver answered "rarely" in the first interview and "almost always" in the second, whereas in the other the caregiver changed the answer from "always" to "never".

Question 14, "Do you feel that your relative seems to expect you to take care of him/her, as if you were the only one he/she could depend on?" shows an even distribution of the answers and the greatest divergences were those found in the questions related to the feeling that the family relative sometimes expects to be cared for exclusively by the caregiver. The six subjects in the first interview changed to 10 subjects in the second one. In other words, from the family relatives that chose the answer "sometimes" in the first interview, 3 answered "never" and "rarely" and 3 answered "very frequently" and "almost always" in the second interview. The 10 subjects who marked this answer in the second interview chose answers ranging from "never" to "almost always" in the first interview, although none of them chose "sometimes". In addition, there were two significant divergences, in which the answer "never" changed to "almost always". It became evident that question 14 had not been fully understood in the distribution analysis of the answers on the polychotomous measurement level. Here, the variations did not follow any justifiable pattern, such as a change of feeling as to the phenomenon. On the other hand, this did not occur in other low-reliability questions.

In question 21, "Do you feel you could do a better job at caring for your relative?" during the first interview the answers tended to be concentrated on the belief that caregiving could not be improved ( $\mathrm{n}=36$ : "sometimes", "rarely", and "never"), whereas in the second interview the scores tended to increase, thus considering such a possibility. This tendency was not observed by five subjects, one of whom changed the answer from "rarely", to "never" and four of whom changed their answers from "nearly always" to "never" and "rarely" In general, it was noted that the family caregiver was eventually inclined to consider that his or her caregiving tasks could be improved.

\section{Discussion}

The Brazilian version of the ZBI proved to be easy to administrate to the dementia patients' caregivers and also reliable, with overall relia- bility rates that were comparable to those of previous studies 5,6,7. This is supported by the fact that the profile of the selected caregiver was similar to that of the original study 12 . In the latter, two-thirds of the patients needed the caregivers' assistance to perform at least one daily activity, which required intensive care. Furthermore, by selecting subjects from services with different socioeconomic standards among the assisted patients, it was possible to obtain variability in the levels of acceptable answers to each of the questions. The authors therefore observed that only 6 questions of the 22 contained in the instrument could not be evaluated on the polychotomous measurement level.

The present study also shows the reliability rates for each of the questions. Although this is not usually presented in the available literature, the authors believe that it is an important aspect that could be useful in the elaboration of this version of the instrument. In general, the instrument demonstrates "good" reliability, with the exception to six questions. The authors believe that this outcome resulted from two problems, namely, variation in the information because the question had not been fully understood and occasional variations arising from the chosen study design.

Question 14 was the one that showed "low" reliability, probably due to problems in the translation. A good translation for this question can be found in the study by Scazufca 13 .

The authors believe that the "low" reliability of the remaining questions was due to occasional variations. This is because the pattern of alterations in the answers can be explained by a variation in the phenomenon discussed in this study. For example, to diminish the stress, as in question 3; to feel less afraid of what might happen to the family member in the future, in question 7; to feel that one's health has been affected, in question 10; only rarely feeling that one's social activities have been affected, in question 12; and being inclined to feel that the caregiving tasks could be improved, in question 21 .

The subject's interaction with this kind of instrument could lead to reflections on the questions and lead to variation in the abovementioned phenomenon. Family members in the present sample were caregivers of patients with a high degree of dependence, as shown before. After the interview, most of the caregivers requested orientation for dealing with the patients. This shows that the interview' had raised doubts and careful consideration and may have altered their evaluation of the impact of caregiving. Consequently, being able to discuss the problems involved in the caregiving 
task could have diminished stress and fear, simply because of the feeling that such problems had been understood. Careful consideration of this issue may also have resulted in the awareness of some aspects that had not been noticed previously, such as anxiety about not being able to do a good job. These considerations have raised two important issues: the possible impact of this type of interview, especially with subjects who have already been exposed to these reflections, and the need to provide support and information to these people.

Finally, the authors conclude that this version of the ZBI has proven reliable for measuring caregiver burden with dementia patients. In some of the questions the reliability was

\section{Resumo}

O objetivo deste estudo foi avaliar a confiabilidade da versão brasileira do Inventário de Sobrecarga do Cuidador em familiares de pacientes com demência. O Inventário consiste em 22 questões que avaliam o impacto das atividades de cuidados nas esferas física, psicológica e social. O instrumento foi aplicado a 50 cuidadores captados em três diferentes centros e o método utilizado foi o teste-reteste. A análise dos resultados mostrou coeficiente intra-classe de 0,88 e Alpha de Cronbach de 0,77 e 0,80 no teste e no reteste, com resultados comparáveis ao estudo original, mostrandose confiável para ser utilizado como uma medida da sobrecarga apresentada pelos cuidadores de pacientes com demência.

Demência; Cuidadores; Cuidados Domiciliares de Saúde

\section{References}

1. Haley WE. The family caregiver's role in Alzheimer's disease. Neurology 1997; 48:25-9.

2. Whitlatch CJ, Zarit SH, Eye A. Efficacy of interventions with caregivers: a reanalysis. Gerontologist 1991; 31:9-14.

3. Karsch UMS. Envelhecimento com dependência: revelando cuidadores. São Paulo: Educ; 1998.

4. Zarit SH, Orr NK, Zarit JM. The hidden victims of Alzheimer's disease; families under stress. New York: New York University Press; 1985.

5. Arai Y, Kudo K, Hosokawa T, Washio M, Miura H, Hisamichi S. Reliability and validity of the Japanese version of the Zarit caregiver burden interview. Psychiatry Clin Neurosci 1997; 51:281-7.

6. Demers A, Lavoie JP. Effect of support groups on family caregivers to the frail elderly. Can J Aging 1996; 15:129-44.

7. Lee YR, Sung KT. Cultural influences on caregiving burden: cases of Koreans and Americans. Int J Aging Hum Dev 1998; 46:125-41.

8. Hébert R, Bravo G, Préville M. Reliability, validity lower, for several possible reasons, including cultural ones. Since the reliability study of each of the questions had not been previously studied for other versions of this scale, the authors cannot compare their results.

\section{Conclusion}

The Brazilian version of the ZBI employed in the present study is a reliable instrument to be used as a measure of the dementia caregiving burden. The rate of reliability proved to be comparable to the original version and is a useful instrument to be applied both in research and clinical practice.

\section{Contributors}

A. Taub contributed to the concept, data acquisition, data interpretation, drafting, and approval of the final version of the article. S. B. Andreoli collaborated in the study design, data analysis and interpretation, and drafting and approval of the final version. P. H. Bertolucci participated in the study concept and design, data interpretation, and drafting and approval of the final version. and reference values of the Zarit Burden Interview for assessing informal caregivers of community-dwelling older persons with dementia. Can J Aging 2000; 19:194-507.

9. Rosner B. Fundamentals of biostatistics. California: Duxbury Press; 1995.

10. Cronbach LJ. Coefficient alpha and the internal structure of test. Psychometrika 1951; 16:297-334.

11. Landis JR, Koch GG. The measurement of observer agreement for categorical data. Biometrics 1977; 33:159-74.

12. Zarit SH, Reever KE, Bach-Peterson J. Relatives of impaired elderly: correlates of feeling of burden. Gerontologist 1980; 20:649-55.

13. Scazufca M. Brazilian version of the Burden interview scale for the assessment of burden of care in carers of people with mental illnesses. Rev Bras Psiquiatr 2002; 24:12-7.

Submitted on $05 /$ Jun $/ 2003$ Approved on 18/Aug/2003 